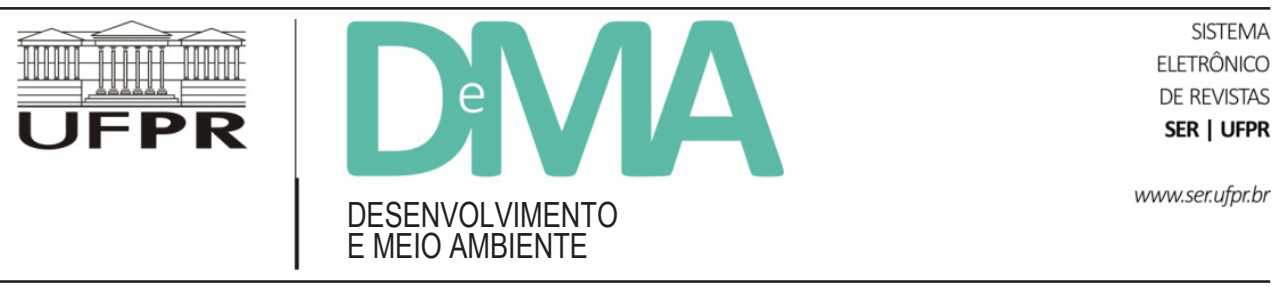

\title{
População tradicional, Reservas Extrativistas e racionalidade estatal na Amazônia brasileira
}

\section{Traditional Population, Extractive Reserves and State Rationality in the Brazilian Amazon}

\author{
José Bittencourt da SILVA ${ }^{*}$, Ligia Terezinha Lopes SIMONIAN ${ }^{2}$ \\ ${ }^{1}$ Programa de Pós-Graduação em Educação (PPGED), Instituto de Ciências da Educação (ICED), Universidade Federal do Pará (UFPA), \\ Belém, PA, Brasil. \\ ${ }^{2}$ Programa de Pós-Graduação em Desenvolvimento Sustentável no Trópico Úmido (PPGDSTU), Programa de Pós-Graduação de Gestão Pública \\ (PPGPG), Universidade Federal do Pará (UFPA), Belém, PA, Brasil. \\ *E-mail de contato: jbsilva@ufpa.br
}

Artigo recebido em 10 de maio de 2014, versão final aceita em 19 de fevereiro de 2015.

RESUMO: As populações tradicionais amazônicas - particularmente aquelas residentes em Reservas Extrativistas (RESEX) florestais - possuem ligação histórico-valorativa com o chamado sistema de aviamento. Essas populações enfrentam um dilema estrutural que precisa ser superado, qual seja: desvencilhar-se das amarras práticas e axiológicas herdadas da ambiência do barracão e aprender a complexa tarefa de movimentar-se dentro da arquitetura racional-legal do Estado brasileiro. Ao se pautar em processos legalmente estatuídos, essa realidade nova inflige aos agentes deste campo do conhecimento e capacidade argumentativa (fortalecimento) para a objetivação de demandas peculiares como, por exemplo, a segurança fundiária e a proteção dos ecossistemas naturais. Este artigo tem como objetivo principal revelar tal dilema das populações extrativistas moradoras de RESEX florestais na Amazônia, analisar suas nuances e lançar luzes para a superação dessa realidade. O trabalho pode ser caracterizado como uma crítica ao formalismo estatal, que tem servido à dominação de agentes públicos sobre unidades de conservação da natureza e das pessoas envolvidas nesses territórios. Para a consecução do objetivo traçado, buscou-se fundamentação teórica em bibliotecas virtual e física, assim como em acervo pessoal dos autores. O que segue são aprofundamentos acerca do objetivo levantado, a partir da literatura examinada.

Palavras-chave: população tradicional; Reservas Extrativistas; racionalidade estatal.

ABSTRACT: Amazone traditional populations - particularly those living in Forestry Extractive Reserves (RESEX) - have a historical and value connection with the system called "sistema de aviamento". Such populations face a structural dilema that need to be surmounted: to destroy the practical and axiological impediments inherited from the ambience of the "barracao" and learn the complex task to move within the rational and legal arquiteture of the Brazilian State. When based on legally institutionalysed processes, such new reality imposes agents of this field of knowledge sphere and argumentation capacity (empowerment) an objectivation of peculiar demands 
as, for example, land security and a natural ecossystem protection. The purpose of this paper is to reveal such dilema of extrative populations who live in in the RESEX in the Amazon, to analyse its nuances and to offer ideas to surmount such reality. This work can be deemed as a critique to state formalism, that has contributed to the domination by public agents of Conservation Units and envolved individuals in such territories. In order to achieve the proposed goal, we made a reserach on theoryc fundamentation in virtual and physical libraries, as well as in the personal files of authors. What follow are analysis of the main objective, based on the studied books and works.

Keywords: traditional population; Extractive Reserves; state rationality.

\section{Introdução}

Segundo a mitologia grega, Édipo, rei de Tebas, enfrentou uma longa jornada em seu passado na busca pela conclusão de seu inexorável destino: matar seu próprio pai e desposar sua mãe. Nesta épica caminhada, Édipo deparou-se com uma esfinge no meio do deserto. Com corpo de leão e cabeça de gente, a escultura teria expressado ao herói grego a seguinte fala: decifra-me ou te devoro (Sófocles, 2011). Assim, caso não respondesse à pergunta formulada pela esfinge, ele seria castigado com a sentença de morte. Era, portanto, necessário saber as respostas certas para continuar a viagem. Ao responder corretamente ao enigma lançado, Édipo salvou a sua vida e a cidade de Tebas.

Do mesmo modo, as populações tradicionais da atualidade, em sua trajetória pela efetivação das próprias utopias, ${ }^{1}$ colocam-se à frente do Estado nacional brasileiro com um problema edipiano similar: decifrar e aprender como se movimentar segundo a lógica da racionalidade estatal moderna ou ser dominado pela burocracia. De fato, esse enigma é ao mesmo tempo um obstáculo e uma condição para a superação dos gargalos que entravam os processos de melhoria individual e coletiva dessas populações, em particular aquelas residentes em Unidades de Conservação de Uso Sustentável (UCUS), como as Reservas Extrativistas (RESEX) ${ }^{2}$.

O presente artigo expõe e analisa esse confronto dilemático entre as práticas tradicionais das populações residentes em RESEX, historicamente ligadas a valores e processos não formais de conduta, frente à lógica racional do Estado brasileiro, que exige relações de papéis preestabelecidas formalmente pelos estatutos. Precisamente, o que se deseja analisar são as dificuldades dessas populações para proceder a uma conduta balizada em marcos legais, o que exige conhecimento, habilidade argumentativa e edificação de uma cultura organizativa.

Ressalte-se que há aspectos da formação, desenvolvimento e manutenção do Estado brasileiro ${ }^{3}$ que lhe dão tonalidades próprias, as quais não se devem negligenciar quando se pretende entender as possíveis relações entre o público e o privado no território nacional. É exatamente por isso que não se pode transplantar uma teoria do Estado, ou de sua burocracia, sem que se façam as devidas ressalvas e mediações quanto ao seu processo histórico de formação, para que se entenda o seu funcionamento na atualidade.

Não está no escopo deste artigo aprofundar debates teóricos sobre o Estado moderno e sua burocracia na Europa e no Brasil, nem tampouco haveria espaço para isso neste momento, na medida em que essas discussões necessitariam de aprofundamentos teórico-conceituais em contextos históricos diferentes, o que exigiria um maior fôlego explicativo. Por ora, importa saber que as populações tradicionais precisam resolver esse dilema (aprender como se movimentar segundo a racionalidade estatal moderna ou ser dominado por ela) no contexto de uma esfera jurídico-política que ainda não se modernizou

\footnotetext{
1 Utopia no sentido positivo do termo, ou seja, como ideias-força que movem as pessoas na busca pela realização de desejos ainda não materializados no presente, ou ideias que tendem à modificação do status quo vigente (Galeano, 2007).

2 O foco deste artigo nas populações tradicionais que moram em RESEX se dá porque os autores apresentam um background importante junto à realidade dessas UC. Todavia, o debate apresentado pode ser espraiado para outros locais e populações amazônicas que apresentam processos históricos similares de formação, como é o caso das quilombolas, ribeirinhas, caboclas, etc.

3 Ou do modus operandi de suas organizações.
} 
plenamente, ${ }^{4}$ ou, como quer Brito (2001), modernizou-se superficialmente.

Brito (2001) faz uma exposição teórica acerca da especificidade do processo de formação e atuação do Estado brasileiro, tanto em nível nacional como local-amazônico. A tese defendida pelo autor foi a de que os processos que deram origem à economia nacional capitalista industrial brasileira (mormente a partir dos anos de 1930), assim como o seu desenvolvimento e consolidação, não conseguiram modificar

[...] as relações patrimonialistas sustentadas por uma cultura autoritária. A facilidade com que surgem novos esquemas de reprodução das estruturas, que são a marca da relação Estado e sociedade, demonstra a existência de obstáculos para o enraizamento do princípio da racionalização de fins e meios no seio das instituições políticas, caracterizando, assim, a modernização da superfície (Brito, 2001, p. 22).

O que se observa a partir de Brito (2001) é que o projeto de construção de uma racionalidade moderna ocidental europeia ainda não se consolidou no Brasil. Para este autor, as relações formais brasileiras estão clivadas de intencionalidades, principalmente de grupos que se apropriam dos aparelhos de estado e locupletam-se utilizando a formalidade legal. É por isso que se afirma que no Brasil a corrupção é estrutural às suas organizações estatais, haja vista que elas são a fonte de enriquecimento de elites burocráticas, assim como é a base do aumento da fortuna das classes sociais dominantes no país.

No Brasil (e em particular na Amazônia) a esfera estatal ainda está longe de ser um espaço dominantemente balizado pelo ordenamento jurídico e pela ética ${ }^{5}$ do fazer estatutário, em que pese haver um conjunto de normas criadas e que poderiam servir de lastro para tais condutas. Na verdade, o que se tem de fato são interesses elitistas e classistas, que têm dificultado os processos de participação dos grupos e classes sociais trabalhadoras.
Metodologicamente, o artigo foi construído com base em pesquisa bibliográfica (Carvalho, 1995; Santos, 2001; Severino, 2007) realizada em bibliotecas física e virtual e em acervo pessoal. Para a exposição conceitual acerca das populações tradicionais e as RESEX na Amazônia, foram de fundamental importância autores como Balée (1989), Allegretti (1994), Diegues (1993; 1996), Roué (1997), Cunha \& Almeida (2001), Silva (2003; 2007; 2010a), Simonian (2000; 2003; 2007) e Vianna (2008). Quanto às argumentações sobre a estrutura racional/legal do Estado e o fortalecimento necessário dessas populações via educação, foram imprescindíveis os trabalhos de Freire (1983; 1997; 2001), Weber (1992; 1996), Schiavo \& Moreira (2005), Gadotti (2008), dentre outros.

Além desta introdução e das considerações finais, o artigo está dividido em três partes, a saber: primeiro, buscou-se apresentar o significado do conceito de população tradicional, o qual está historicamente relacionado com o movimento socioambiental dos seringueiros do Acre, bem como com o processo de institucionalização das primeiras RESEX na Amazônia. Após essas definições conceituais, apresentou-se em seguida o dilema edipiano das populações tradicionais já mencionado acima, qual seja: aprender como agir segundo a lógica racional-legal do Estado Nacional Brasileiro ou ser dominado por sua burocracia.

Note-se que neste artigo colocou-se a Educação Escolar de crianças, jovens e adultos como componente importante no processo de construção de uma qualidade histórica necessária ${ }^{6}$ para a modificação da realidade/ problema vivenciada pelas populações tradicionais amazônicas. Precisamente, apresentou-se a escolarização como capaz de contribuir com a construção da qualidade histórica dessas populações, não só no que concerne ao processo de desenvolvimento cognitivo, mas fundamentalmente para a sua organização participativa, na busca pela autodeterminação, afirmação de direitos e resolução de demandas locais. O que segue são aprofundamentos

\footnotetext{
4 Para Giddens (1991, p. 11), a modernidade “[...] refere-se a estilo, costume de vida ou organização social que emergiram na Europa a partir do século XVII e que ulteriormente se tornaram mais ou menos mundiais em sua influência”.

5 Campo que exigiria de cada um e de todos uma ação social baseada em meios e fins.

6 Freire $(1980 ; 1997 ; 2001)$ afirma que nós somos seres inconclusos e a educação deve ser implementada no sentido de contribuir com nossas incompletudes. Para este autor, educar deve ser um processo que se realiza no devir histórico, com objetivo determinado de qualificar e empoderar pessoas para que se percebam e percebam o mundo de maneira autônoma, crítica e emancipatória.
} 
acerca da problemática levantada a partir da literatura examinada.

\section{População tradicional: sentido e significado do conceito na Amazônia}

O conceito de população tradicional, que emergiu na Amazônia brasileira nas décadas de 1970/1980, faz parte de uma constelação de situações teóricas e práticas produzidas no âmbito das demandas fundiárias e socioambientais dos grupos humanos que se estabeleceram na região, em particular no contexto do chamado ciclo da borracha. No Acre, os seringueiros, inicialmente chamados de Povos da Floresta face à similaridade ou identificação de suas atividades socioeconômicas com o modo de vida indígena (Allegretti, 1994; Simonian, 2000; Silva, 2003; 2007), constituíram-se nos principais sujeitos protagonistas que estabeleceram o enfrentamento dos novos processos de ocupação dos ecossistemas locais via corte, queima, formação de pasto e criação de gado.

Para Castro (1998), esse é um momento de efervescência de um ambientalismo global que identificava nos indígenas, ribeirinhos, quilombolas, seringueiros e outros um referencial importante para a proteção da biodiversidade amazônica. Assim, a conjuntura ambiental planetária, os processos de ocupação da Amazônia no contexto do regime militar, suas externalidades e os anseios das populações extrativistas locais geraram as condições objetivas para a construção do conceito de população tradicional. Por isso, a ideia de sustentabilidade ambiental é apresentada como condição indispensável à formação conceitual dessas populações.

Há uma infinidade de críticas à concepção de população tradicional ligada à conservação da natureza in situ. Neste contexto, é de se citar o trabalho de Vianna (2008), o qual se baseia na realidade de Unidades de Conservação da Mata Atlântica, ou no que restou delas nos Estados de São Paulo e Rio de Janeiro. Na obra, a autora afirma que, em seu nascedouro (décadas de 1970/1980/1990), o conceito de população tradicional era vago, impreciso e com uma relação quase nula com os processos da vida real das populações locais.

Balizados pela teoria do bom selvagem, os autores que construíram esse conceito ${ }^{7}$ teriam apresentado as populações tradicionais como aquelas que vivem em harmonia com a natureza, dicotomicamente colocadas frente à sociedade nacional dominante (Vianna, 2008). Tais ideias teriam sido encampadas pelo movimento ambientalista e por seringueiros da Amazônia, e estes passaram a utilizar o conceito de maneira política, objetivando garantir o “[...] acesso a seus territórios e ao uso dos recursos naturais" (Vianna, 2008, p. 22).

Deste modo, longe de ser uma categoria com valor heurístico, o conceito de população tradicional teria, no sentido preservacionista do termo, um valor muito mais político e ideológico do que propriamente acadêmico-científico. O estudo de caso da autora demonstrou que muitas populações locais residentes em UC na Mata Atlântica passaram a utilizar a nomenclatura de populações tradicionais de maneira estratégica, em decorrência de possíveis ganhos advindos das políticas públicas ou ações de organizações não governamentais (ONGs) voltadas às causas ambientais.

A tese levantada por Vianna (2008, p. 24) foi a de que o conceito de população tradicional "[...] se consolidou por meio de diplomas legais, de políticas públicas e pela apropriação da expressão pelos movimentos sociais, como um instrumento de fortalecimento da luta pelo acesso à terra e ao uso dos recursos naturais". Evidentemente que o aspecto da sustentabilidade ambiental como elemento constitutivo do conceito de população tradicional precisa ser relativizado, principalmente no que se refere ao atual momento de homogeneização do território ${ }^{8}$ nacional, fortemente marcado por uma sociedade calcada na racionalidade instrumental, capitalista e mercadológica (Engels \& Marx, 2003).

\footnotetext{
7 Vianna (2008) cita Antônio Carlos Diegues como o ideólogo principal do processo de construção acadêmica do conceito de população tradicional, precisamente como população que vive em simbiose com a natureza.

8 Território no mesmo sentido dado por Costa (2007), ou seja, como processo de domínio (político-econômico) e/ou apropriação (simbólicocultural) de uma parcela do espaço por determinados grupos humanos, os quais se encontram condicionados pelo movimento peculiar do devir histórico.
} 
Ao longo desse processo homogeneizante, as necessidades de sobrevivência obrigam, muitas vezes, ribeirinhos, quilombolas, caboclos, seringueiros, pescadores artesanais, indígenas, etc., a realizarem antropizações nefastas ao meio ambiente, impactando os ecossistemas de maneira nada sustentável. Simonian (2000, p. 10) chama essa realidade de manejo negativo, que seria a "[...] exploração dos recursos naturais feita de modo destrutivo". Isso ocorre porque as populações tradicionais são geralmente cooptadas por parte de setores do Estado e por particulares, com visão voltada exclusivamente para o mercado e os ganhos imediatos que possam adquirir. Pelo que Simonian (2007) ressalta, a problemática da corrupção e outras questões antidemocráticas podem perpassar a realidade de tais segmentos humanos, o que acarreta desdobramentos antipopulações tradicionais.

Por outro lado, Castro (1998, p. 5) busca demonstrar que é o próprio processo produtivo e reprodutivo das condições de produção e de vida que liga essas populações ao "[...] regime dos rios, a reprodução das espécies e o ritmo da natureza". Autores como Balée (1989), Diegues (1996; 1993), Roué (1997) e Simonian (2003), dentre outros, apontam várias características que podem servir de fio condutor à compreensão conceitual dessas populações na Amazônia. Dentre essas características é de se destacar:

I) modo de vida dependente dos ciclos naturais; II) saber familiar-comunitário transmitido de geração em geração e com concomitante elaboração de estratégias de uso e manejo da natureza; III) Noção de território onde o grupo se reproduz econômica, biológica e socialmente; IV) Produção voltada à subsistência familiar, doméstica ou comunal, ainda que uma parte desses produtos seja vendida em mercados locais; V) Construção simbólico-mítica associada à floresta e aos recursos hídricos; VI) Domínio quase completo dos processos produtivos, com utilização de tecnologia de baixo impacto e com predomínio artesanal e; VII) Sentimento de pertença a uma cultura distinta, particularmente em relação às sociedades urbanas (Diegues, 1993, p. 248-249)

Como se observa acima, para estes teóricos o fundamento do conceito de população tradicional reside na relação quase simbiótica entre o modo de vida peculiar desses grupos humanos e a natureza.

Em virtude da estreita dependência dos ecossistemas locais, certas populações acabam por realizar uma antropização de baixo impacto ambiental e, em muitos casos, melhoram qualitativa e quantitativamente a biodiversidade local, como atestou Diegues (2001, apud Guerra \& Coelho, 2009, p. 29).

[...] As práticas culturais de manejo dos recursos naturais desenvolvidas por algumas dessas populações interagem com o processo evolutivo das espécies há milhares de anos, de modo que a presença das populações e o manejo que fazem de determinados ecossistemas são essenciais à manutenção da biodiversidade. $\mathrm{O}$ caso dos maasai é um exemplo, pois a implantação de parques e a retirada desse povo que manejava a paisagem de savana em regiões da Tanzânia e do Quênia, com queimadas periódicas, levaram à continuidade do processo de sucessão ecológica, de modo que áreas anteriormente cobertas por herbáceas passaram a ser dominadas por arbustos, com redução nas populações de grandes mamíferos.

O tipo mais puro dessas populações são os indígenas, como se depreende de Kern (2014), o qual observa que são eles fundamentais na manutenção e no melhoramento de partes relevantes dos ecossistemas do bioma Amazônia, a exemplo do que ocorreu nos castanhais, nos balatais e nas terras pretas de índio - TPI, todas fertilíssimas ${ }^{9}$.

\footnotetext{
9 As TPI estão comumente localizadas ao longo de rios e interflúvios, ocupando várzeas e terra firme na Amazônia. Esses espaços são resultado da ação antrópica pré-colonial de populações autóctones que, ao desenvolverem suas atividades de vivência e sobrevivência na floresta, acabaram produzindo solos de coloração escura, com “[...] alto teor de Ca, Mg, Zn, Mn, P e C” (Kern, 2014, p. 72). Essa coloração das TPI deve-se à “[...] presença de material orgânico decomposto, em parte na forma de carvão residual de fogueiras domésticas e da queima da vegetação para uso agrícola do solo. Os elevados teores de C orgânico, bem como os de P, Ca e de Mg, são resultantes da deposição de cinzas, resíduos de peixes, conchas, caça, dejetos humanos, entre outros compostos orgânicos. Por essa razão, a fertilidade química da TPI é significativamente superior à maioria dos solos amazônicos não perturbados pela atividade humana pré-histórica, geralmente ácidos e pobres em nutrientes”.
} 
É com base em características como essas colocadas acima que o conceito de populações tradicionais vem sendo pouco a pouco habitado por pessoas reais, as quais estão pautando suas demandas e exigindo do Estado brasileiro políticas públicas ${ }^{10} \mathrm{e}$ ações de governo voltadas especificamente às suas necessidades. Assim, desde a criação das primeiras RESEX em 1990, que se constituiu no primeiro grande ganho das populações tradicionais amazônicas, observa-se que o governo federal vem propondo e/ou implementando projetos, programas e políticas voltados especificamente a essas populações, assim como criou organizações governamentais com objetivos voltados à gestão de territórios habitados por populações tradicionais ${ }^{11}$.

Foi esse movimento, ora protagonizado por sujeitos sociais e suas demandas locais, ora por cientistas sociais ligados às causas ambientais, que fez emergir no campo estatal um conjunto de leis e regulamentações voltadas às demandas das populações tradicionais. Deste modo, a primeira grande definição legal sobre elas encontra-se na Lei 9.985/2000, que criou o Sistema Nacional de Unidades de Conservação da Natureza - SNUC. Conforme Brasil (Art. 18, 2000), pode-se ler que as populações extrativistas tradicionais são aquelas "[...] cuja subsistência baseia-se no extrativismo e, complementarmente, na agricultura de subsistência e na criação de animais de pequeno porte".

Entretanto, pode-se dizer que a conceituação mais consistente elaborada no campo legislativo está contida no Decreto $n^{\circ} 6.040 / 2007$, que legalizou a Política Nacional de Desenvolvimento Sustentável dos Povos e Comunidades Tradicionais, como se lê a seguir.
[...] grupos culturalmente diferenciados e que se reconhecem como tais, que possuem formas próprias de organização social, que ocupam e usam territórios e recursos naturais como condição para sua reprodução cultural, social, religiosa, ancestral e econômica, utilizando conhecimentos, inovações e práticas gerados e transmitidos pela tradição (Brasil, 2007, Art. $3^{\circ}$, I).

Ao levar-se em consideração as arguições teóricas e conceituais acima, assim como as proposições doutrinárias do Estado Nacional Brasileiro, entender-se-á por população tradicional como aquela que, por apresentar um modo de vida próprio e dependente dos ciclos naturais tende, em essência, à manutenção ecossistêmica dos territórios onde habitam, imbricando ecologicamente produção e reprodução econômica e sociocultural com a própria natureza circundante.

\section{População tradicional e racionalidade estatal no contexto das Reservas Extrativistas}

Pode-se entender o Estado como um campo ${ }^{12}$ burocrático relativamente autônomo, clivado por relações de poder e dominação, no qual os agentes envolvidos neste espaço estão condicionados pela ética das relações formais, com princípios estabelecidos previamente por um marco legal ${ }^{13}$. Precisamente, as condutas das pessoas neste campo são balizadas por estatutos aceitos pela maioria dos participantes como legítimos, ou seja, ações tidas como racionais porque apresentam meios e fins que já estão previamente estipulados ou estabelecidos

10 Política pública “[...] significa o Estado em ação, promoção, pelo Estado, de formas de executar aquilo que está no âmbito de seus deveres [...]", entendido este Estado como "[...] uma relação social, ou melhor, a condensação das relações presentes numa dada sociedade. E é exatamente o resultado das forças presentes nessa condensação das relações sociais que faz o Estado agir, ou seja, que o faz conceber e executar essa ou aquela política pública" (Gramsci, apud Molina, 2012, p. 591).

11 Nessa perspectiva, tem-se o Instituto Chico Mendes de Conservação da Biodiversidade - ICMBio.

12 Com base nas concepções teóricas de Bourdieu (1996), pode-se dizer que o campo é ao mesmo tempo uma arena de forças constrangendo aqueles que nele se inserem, e também um espaço de confronto e luta, no qual a conduta dos agentes liga-se a posições e interesses individuais ou grupais, ou na busca pela modificação do estado de coisas próprio de cada campo ou pela manutenção de suas estruturas.

13 Essa percepção de cunho weberiano precisa ser relativizada no Brasil, face as características do atual momento do devir histórico estatal brasileiro, ou seja, um Estado híbrido pautado na racionalidade formal, mas convivendo fortemente com modalidades de relações políticas clientelistas e patrimonialistas (Brito, 2001). 
em lei, ou, como afirma Weber (1992), uma esfera de dominação ${ }^{14}$ racional/legal.

De fato, por ser uma esfera da vida humana caracterizada pela dominação racional/legal, a ação dos agentes participantes do campo burocrático legitima-se pelas regras do jogo. Pode-se mesmo perceber a arena estatal burocrática a partir da visão weberiana da ação comunitária

[...] na medida em que 1) se orienta, de maneira significativa, por expectativas que são alimentadas com base em regulamentações, 2) na medida em que tal "regulamentação" foi feita de modo puramente racional com relação a fins, tendo em mente o agir esperado dos associados como consequência, e quando 3) a orientação provida de sentido se faz, subjetivamente, de maneira racional com relação a fins (Weber, 1992, p. 325).

Por isso, é possível dizer que quanto maiores o conhecimento e as habilidades jurídicas (gerais e específicas) no âmbito das organizações burocráticas estatais, maiores serão a influência e a disposição em encontrar obediência a determinado conteúdo junto às demais pessoas componentes do campo. $\mathrm{O}$ inverso também é verdadeiro, ou seja, aqueles que se aventurarem a entrar neste campo sem a qualificação necessária estarão fadados a serem engolidos pelos que dominam as regras do jogo.

É exatamente nessa realidade racional/legal que muitas populações amazônicas estão sendo inseridas de maneira categórica. Esse é o caso das populações extrativistas tradicionais que estiveram durante muito tempo à margem dos processos racionais/legais do Estado Brasileiro e agora residem em Unidades de Conservação da Natureza, como as RESEX, que são territórios do espaço nacional brasileiro, criados legalmente e inseri- dos na dinâmica do campo burocrático-administrativo estatal que tem submetido os moradores locais à lógica do campo burocrático estatal ${ }^{15}$. Contudo, a maioria dessas populações (ou ao menos suas lideranças) não teve o devido preparo para essa nova realidade, que exige expertise e capacidade de aplicação de conhecimentos baseados nos estatutos.

Assim posto, observa-se que as ações dessas populações tradicionais em áreas de RESEX devem estar balizadas na formalidade das regulamentações estipuladas por estatutos legais, ou seja, suas práticas de uso ou manejo dos recursos naturais dentro do território demarcado deverão pressupor o que está normatizado nas leis, decretos, portarias, resoluções, regimentos, etc., uma realidade formal própria do campo burocrático-administrativo estatal. Todavia, essa nova realidade precisa ser debatida e compreendida, pois as populações tradicionais, que se adaptaram às realidades ambientais amazônicas há centenas de anos, sempre estiveram ligadas a um modo de vida baseado em valores comunitários não formais,${ }^{16}$ repassados de geração a geração e cristalizados através dos tempos.

Essa consciência coletiva pretérita (Durkheim, 2004) constituiu-se (e ainda se mantém) na base valorativa sobre a qual se efetivaram (e ainda se efetivam) as condutas individuais e coletivas das populações tradicionais amazônicas. O resultado disso é que essas populações não possuem a cultura da ação formal exigida pelo campo burocrático-administrativo estatal, constituindo-se em um hábito a ser construído. Isso tem gerado inúmeras dificuldades para essas populações quando desejam movimentar-se dentro da estrutura do Estado na busca pelo acesso a benefícios sociais ou trabalhistas.

O processo modernizante e de incorporação da Amazônia ao espaço nacional brasileiro via capital nacio-

14 Sociologicamente falando, para Weber (1996, p. 10-14) a dominação é um caso especial do poder, este visto em seu sentido mais geral como “[...] a possibilidade de impor a própria vontade sobre a conduta alheia [...]. Por conseguinte, entendemos aqui por 'dominação' um estado de coisas pelo qual uma vontade manifesta ('mandato') do 'dominador' ou dos 'dominadores' influi sobre os atos de outros (do 'dominado' ou dos 'dominados'), de modo que, em um grau socialmente relevante, tais atos tenham lugar como se os dominados tivessem adotado por si mesmos, e como máxima de seu operar, o conteúdo do mandato ('obediência')".

15 É evidente que essas populações viveram dentro do Estado Nacional Brasileiro, portanto sujeitas às leis nacionais, como, por exemplo, o código florestal. Todavia, esse marco legal e os órgãos estatais garantidores dessa legalidade nunca estiveram tão próximos dos extrativistas da Amazônia como nos dias atuais.

16 Não escritos, ou consuetudinários. 
nal e, principalmente, estrangeiro (Becker, 2004) fez com que as populações tradicionais passassem a fazer parte da racionalização burocrática e administrativa própria da estrutura estatal, mas sem o devido preparo para isso. Por outro lado, apesar de possuírem em seu nascedouro uma história de lutas e conquistas sociais frente a empresas privadas capitalistas, as RESEX configuram-se na atualidade como a materialização dessa racionalidade estatal e, como tal, exigem ações pautadas em regras legalmente criadas (Weber, 2004).

De fato, os processos de inserção das populações tradicionais no campo burocrático-administrativo estatal via UC exigem agora uma adequação à lógica de relações de papéis, definida previamente por normas legais. Isso vem gerando grandes dificuldades para o desenvolvimento comunitário local, na medida em que as contradições entre o tradicional e o moderno se confrontam neste campo. A necessária separação entre público e privado, a criação de associações comunitárias e cooperativas com seus estatutos, reuniões ordinárias, construção de atas e relatórios, implementação de ações coletivas e prestações de contas são realidades sui generis para populações historicamente ligadas a processos informais, não vinculados a condutas próprias da denominada gaiola de ferro da burocracia (Weber, 1999).

Para além dessa realidade peculiar à sociedade civil organizada local, há por parte dos organismos estatais (Instituto Chico Mendes de Conservação da Biodiversidade - ICMBio, secretarias estaduais e municipais de meio ambiente e outros) a exigência de ações pautadas nos planos de manejo e de utilização dos recursos naturais, zoneamentos econômicos e ecológicos, metodologias de gestão participativa, controle das ações individuais e familiares, sanções e penalidades, conselhos consultivos e deliberativos e muito mais. Essa estrutura racional-legal encontra-se prescrita racionalmente em leis, decretos e estatutos que passam a servir de parâmetro para as ações das diversas das populações tradicionais em seus territórios, agora demarcados como UC, ou, mais especificamente, como RESEX.
Por exemplo, a pesca ou caça sempre foi uma prática comum das populações tradicionais para a aquisição de proteína animal. Todavia, criada formalmente uma RESEX (ou outra UC qualquer), as populações tradicionais não poderão mais simplesmente adentrar os rios ou a mata para apresar, matar e alimentar-se de animais silvestres. A rigor, essa ação historicamente praticada por essas populações somente deveria ser executada se a regulamentação do plano de manejo ou de uso tivesse especificado doutrinariamente a quantidade e as espécies de animais legalmente liberadas para a captura e o consumo como alimento.

Essa ética da ação racional que determina fins e meios é, ao mesmo tempo, um obstáculo e uma condição para a superação de impedimentos que entravam os processos de melhoria individual e coletiva das populações tradicionais residentes em RESEX, principalmente quando os objetivos dessas populações relacionam-se com a garantia de seus territórios (segurança fundiária), proteção ambiental (sustentabilidade ecossistêmica) e condições de saúde e de educação escolar (desenvolvimento comunitário). Entretanto, a adequação necessária a essa racionalidade exige das populações tradicionais um empoderamento ${ }^{17}$ individual e coletivamente, em especial de parte das lideranças locais e dos mecanismos de controle social ou comunitário.

Esse empoderamento pode ser traduzido em condições e capacidade de movimentação das populações tradicionais dentro do campo burocrático-administrativo estatal, caso contrário elas serão dominadas por capitalistas e pela própria burocracia do Estado, os quais, em sua grande maioria, possuem a expertise e os saberes necessários à movimentação dentro do campo. Além desse empoderamento necessário para o trato com e nas organizações que integram o aparelho de Estado brasileiro, as populações tradicionais precisam aprender a tarefa difícil de participar da vida política e partidária em âmbitos municipal, estadual e federal. Afinal, quantos vereadores, deputados estaduais, federais e senadores são representantes legítimos das populações tradicionais?

\footnotetext{
17 Segundo Schiavo \& Moreira (2005), se uma pessoa encontra-se empoderada no contexto social isso significa dizer que ela obteve informações que lhe deram base para a reflexão de sua condição atual e, por isso, é capaz de compreender seu presente e apontar as mudanças desejáveis no futuro. Ela sai de uma condição de objeto para outra de sujeito, abandonado antigas posturas meramente reativas ou receptivas em favor de práticas proativas e transformadoras.
} 
Quais dos mais influentes partidos políticos apresentam propostas de governo construídas com a efetiva participação de lideranças dessas populações?

Pelo que se observa, existem atualmente agentes sociais e políticos que articulam discursos e assumem posições a partir de interesses dessas populações, mas não são populações tradicionais. Como se depreende de Batista \& Simonian (2013), também o Estado vem atuando à revelia dos interesses dessas populações, o que tem dificultado a efetivação de um desenvolvimento comunitário endógeno e sustentável, o que seria essencial. As lutas e conquistas dessas populações devem ser percebidas de maneira processual e as dificuldades são inúmeras nesta caminhada, pois em muitos locais na Amazônia há pessoas que não existem formalmente para o Estado brasileiro, ou seja, não possuem certidão de nascimento ou qualquer outro documento reconhecido pelos órgãos governamentais.

Como observado por Silva (2010b), há entre as populações tradicionais problemas educacionais sérios, tais como o analfabetismo, a baixa escolaridade e o analfabetismo funcional, ou seja, pessoas que frequentaram a escola, mas apresentam extrema dificuldade de leitura e escrita. Ao analisar o processo de desenvolvimento nas RESEX Verde Para Sempre e Arióca Pruanã no Pará, Costa (2014, p. 431) revela que "[...] um fato recorrente é a desistência dos estudos por conta da repetência de série, que se soma ao abandono do curso pela falta de perspectiva em relação ao processo de escolarização, pois esses jovens não vislumbram ascensão social nestas regiões carentes de políticas e ações públicas voltadas para oportunidades profissionais". Mas por certo que existem exceções.

Há também entre essas populações dificuldades para a formação de redes de confiança e solidariedade para além dos espaços domésticos, isto é, há um capital social baixo com dificuldades para a implementação de ações coletivas comunitárias mais gerais, ou que possam ir além dos chamados mutirões (Silva, 2003; 2007). Neste ponto, a questão que se coloca é por onde começar a modificação desse estado de coisas? O que se faz necessário para que as populações tradicionais possam alcançar autonomia e implementação de ações coerentes dentro das estruturais estatais, com objetivos ao desenvolvimento comunitário?
Essas e tantas outras questões concernentes às práticas sociais e políticas das populações tradicionais estão na pauta de suas demandas e se constituem como seus problemas históricos essenciais. Neste particular, a educação escolar pode e deve contribuir com esse processo, sem preterimento dos saberes locais, afinal essas populações possuem um estoque de conhecimento que pode perfeitamente servir de fonte para aquilo que Leff (2011) chamou de ética ambiental, ou seja, uma necessária conduta dos grupos humanos que permita uma cisão com as velhas estruturas do pensamento moderno europeu-ocidental que dicotomizou a vida em sociedade com a natureza.

Não se trata aqui de uma percepção elitista de educação que tem colocado as populações tradicionais sem senso crítico em relação ao estado de coisas vigente em seus processos comunitários e políticos Para tanto, faz-se necessário um rompimento com a chamada educação rural compensatória (Silva, 2014), a qual se caracteriza por ter um currículo urbanocêntrico, professores mal formados, com salários aviltantes e presos ao poder local, com prédios escolares carcomidos e ausência de apoio pedagógico capaz de oferecer metodologias transformadoras ou calcada em uma práxis intrigante (Freire, 1983; 1997; 2001; Gadotti, 2008). Na verdade, a educação que se está reivindicando é aquela que busca relacionar o conhecimento científico com o saber tradicional, que respeita as diferenças, afirma valores grupais, fomenta a autoestima do pensar das pessoas e contribui para a construção de um indivíduo autônomo, crítico e reflexivo.

Neste contexto, a concepção freiriana de educação mediadora da autoconstrução do conhecimento do educando como sujeito pensante é essencial (Freire, 1997). Um exemplo importante nesta direção são as Escolas Famílias Agrícolas (EFA) e as Casas Familiares Agrícolas (CFA) implementadas na Amazônia e alhures (Nascimento, 2010; Silva, 2010b). Nestes espaços educacionais escolares, os educadores/as e monitores/as (todos percebidos como sujeitos educacionais) buscam cotidianamente uma relação ensino-aprendizagem a partir do aprimoramento de experiências já vivenciadas pelos educandos, sem preconceitos ou discriminações das práticas comunitárias ou familiares, geralmente co- 
locadas pela escola de educação bancária ${ }^{18}$ como senso comum, o qual deveria ser abandonado em favor de um conhecimento mais elaborado.

Essas EFAs e CFAs estão fortemente marcadas pelos preceitos do currículo integrado, que pretende fazer a ligação entre os saberes locais com os conhecimentos escolares, tendo na pesquisa e no trabalho princípios educativos inalienáveis. A metodologia efetivada nessas escolas é a chamada pedagogia da alternância (Rodrigues, 2008; Reis, 2011), a qual pretende problematizar a própria realidade dos/as educandos/as, efetivando um percurso formativo que pretende respeitar e unir dialeticamente o tempo na escola e o tempo na família/ comunidade, sem dicotomizar esses dois espaços e percebendo-os como lugares de aprendizagem, formação e educação.

Em suma, faz-se mister uma educação escolar que possa contribuir com o processo emancipatório de autoconhecimento, autoconstrução e autoestima das próprias pessoas em consonância com os outros e com o mundo circundante; uma educação fortalecedora da identidade cultural local, a qual não é pior nem melhor que as outras culturas, que é, na verdade, apenas diferente e poderá contribuir com o desenvolvimento amazônico; uma educação que evidencie que o local onde se está vivendo tem importância econômica, cultural, ambiental e política em escalas local, nacional e mundial.

\section{Considerações finais}

O conceito de população tradicional no contexto amazônico está ligado, intrinsecamente, ao modo de vida de certos grupos humanos ${ }^{19} \mathrm{e}$ à sustentabilidade ambiental de suas práticas socioeconômicas. Pode-se mesmo afirmar que esses grupos são, particularmente, os residentes em RESEX, modelares na atualidade e no que concerne à relação sociedade e natureza. De fato, nos termos de Leff (2011), tais pessoas podem ser tomadas como referência para a construção de uma ética ambiental planetária inovadora.

De fato, esses seres humanos possuem um estoque de saberes e fazeres capazes de informar caminhos novos para percepções novas de mundo ecologicamente corretas. Tal estoque pode balizar condutas imprescindíveis em tempos de aquecimento global, mudanças climáticas, escassez de água potável, desflorestamento e perda de biodiversidade na Amazônia. Todavia, essas populações têm encontrado dificuldades enormes para a objetivação de demandas comunitárias específicas, tais como proteção territorial e ambiental, segurança alimentar, escolarização, saúde, etc. (Silva, 2010b). Esse estado de coisas se dá, dentre outros motivos, pela vulnerabilidade extrema das populações tradicionais frente à estrutura racional/legal do Estado moderno, o qual as inseriu em sua lógica do fazer estatutário sem o devido preparo.

Por isso, importa que lideranças ribeirinhas, quilombolas, extrativistas, enfim, lideranças dos povos amazônicos, aprendam a caminhar dentro dos parâmetros estabelecidos legal e politicamente. Só assim poderão participar e interagir em diversos contextos da realidade burocrático-administrativa estatal peculiar ao campo das relações formais. Em suma, é realmente imprescindível que essas populações participem da vida política e partidária em níveis municipal, estadual e federal, pois somente dessa forma poderão influenciar na proposição e na implementação de políticas públicas voltadas ao desenvolvimento local.

Ainda, não se há de idealizar os grupos humanos de maneira metafísica, descolada das vicissitudes práticas do dia a dia, como se as pessoas não pudessem ou não tivessem interesses e vontades particulares. Aliás, muitas vezes essas são até contrárias aos ditames mais gerais ou coletivos. Entretanto, é importante acreditar

\footnotetext{
18 Freire (1997, p. 67) fala e critica a chamada educação bancária, que para ele é aquela em que: “a) O educador é o que educa; os educandos, os que são educados; b) O educador é o que sabe; os educandos, os que não sabem; c) O educador é o que pensa; os educandos, os pensados; d) O educador é o que diz a palavra; os educandos, os que a escutam docilmente; e) O educador é o que disciplina; os educandos, os disciplinados; f) O educador é o que opta e prescreve sua opção; os educandos, os que seguem a prescrição; g) O educador é o que atua; os educandos, os que têm a ilusão de que atuam, na atuação do educador; h) O educador escolhe o conteúdo programático; os educandos, jamais ouvidos nesta escolha, se acomodam a ele; i) $\mathrm{O}$ educador identifica a autoridade do saber com sua autoridade funcional, que opõe antagonicamente à liberdade dos educandos; estes devem adaptar-se às determinações daquele; j) O educador, finalmente, é o sujeito do processo; os educandos, meros objetos". 19 A saber, indígenas, extrativistas, ribeirinhos, caboclos e outros.
} 
na utopia de que é possível ter ações individuais com objetivos sociais.

Daí a importância da existência de organizações sociais e econômicas estruturadas horizontalmente. Essas formam um sistema interligado de relações com as esferas mais diferentes da vida humana, mormente com a educação, a qual deve ser encarada como essencial nesse processo. Contudo, essa caminhada utópica (no sentido positivo do termo), por mais longa que pareça

\section{Referências}

Allegretti, M. H. Reservas extrativistas: parâmetros para uma política de desenvolvimento sustentável na Amazônia. In: Anderson, A. et al. O destino da floresta: reservas extrativistas e desenvolvimento sustentável na Amazônia. Rio de Janeiro: Relume-Dumará, 1994. p. 17-47.

Balée, W. Cultura na vegetação da Amazônia brasileira. In: Neves, V. A. Biologia e Ecologia humana na Amazônia. Belém: Museu Emílio Goeldi, 1989, p. 95-109.

Batista, I. M. da S.; Simonian, L. T. L. Implicações políticas, econômicas e socioambientais da RESEX Mãe Grande de Curuçá: perspectivas de desenvolvimento sustentável no estuário paraense? Revista Novos Cadernos do NAEA, 16(1), Suplemento, 203-220, 2013.

Becker, B. K. Amazônia: geopolítica na virada do III milênio. Rio de Janeiro: Garamond, 2004.

Bourdieu, P. Razões práticas: sobre a teoria da ação. Campinas: Papirus, 1996.

Brasil. Lei $n^{\circ}$ 9.985, de 18 de julho de 2000. Regulamenta o Art. 225, $\S 1^{\circ}$, incisos I, II, III e VII da Constituição Federal, institui o Sistema Nacional de Unidades de Conservação da Natureza. Diário Oficial [da] República Federativa do Brasil, Poder Executivo, Brasília, DF, 18 jul. 2000. Disponível em: <www.planalato.gov.br>. Acesso em: 11 nov. 2010.

Brasil. Decreto $n^{\circ}$ 6.040, de 7 de fevereiro de 2007. Institui a Política Nacional de Desenvolvimento Sustentável dos Povos e Comunidades Tradicionais. DOU de 7 fev. 2007. Disponível em: <http://www.planalto.gov.br/ccivil_03/_ato20072010/2007/decreto/d6040.htm>. Acesso em: 02 fev. 2013.

Brito, D. C. de. A modernização da superfície. Belém: UFPA/ NAEA, 2001. ser, somente alcançará seu desiderato se forem dados os primeiros passos neste sentido.

As experiências são muitas, como é o caso das EFAs, CFAs e da metodologia da alternância pedagógica a elas ligada. Como proposto por Galeano (2007, p. 310), a utopia é como que uma luz no fim do túnel, um ponto no infinito. Quanto mais se caminha, mais esse ponto fica distante. Então, “[...] Para que serve a utopia? Serve para isso: para caminhar”. Nesse ponto é de se perguntar: por que não tentar?

Carvalho, M. C. M. de (Org.). Construindo o saber. 3. ed. Campinas-SP: Papirus, 1995.

Castro, E. Território, biodiversidade e saberes de populações tradicionais. Paper do NAEA, 92, 1-16, 1998.

Costa, A. P. Políticas públicas e desenvolvimento nas RESEX Verde Para Sempre e Arióca Pruanã - Pará. 504f. Belém, Tese (Doutorado em Desenvolvimento Sustentável do Trópico Úmido) - Universidade Federal do Pará, 2014.

Costa, R. H. O mito da desterritorialização: do fim dos territórios à multiterritorialidade. 3. ed. Rio de Janeiro: Bertrand Brasil, 2007.

Cunha, M. C. da; Almeida, M. W. B. Populações tradicionais e conservação ambiental. In: Capobianco, J. P. R. et al. Biodiversidade na Amazônia brasileira: avaliação e ações prioritárias para a conservação, uso sustentável e repartição de benefícios. São Paulo: Estação Liberdade; Instituto Socioambiental, 2001, p. 184-193.

Diegues, A. C. S. Populações tradicionais em unidades de conservação: o mito moderno da natureza intocada. In: Vieira, P. F.; Maimon, D. (Org.). As ciências sociais e a questão ambiental: rumo à interdisciplinaridade. Belém: APED/NAEA/ UFPA, 1993, p. 219-249.

Diegues, A. C. S. Mito moderno da natureza intocada. São Paulo: UCITEC/NUPAUB-SEC/USP, 1996.

Durkheim, É. Da divisão do trabalho social. 2. ed. São Paulo: Martins Fontes, 2004.

Engels, F.; Marx, K. Manifesto comunista. São Paulo: Instituto José Luís e Rosa Sundermann, 2003. 
Freire, P. Educação como prática da liberdade. 10. ed. Rio de Janeiro: Paz e Terra, 1980.

Freire, P. Educação como prática da liberdade. 17. ed. Rio de Janeiro: Paz e Terra, 1983.

Freire, P. Pedagogia da autonomia. 15. ed. Rio de Janeiro: Paz e Terra, 1997.

Freire, P. Pedagogia do oprimido. 30. ed. Rio de Janeiro: Paz e Terra, 2001.

Gadotti, M. Boniteza de um sonho: ensinar-e-aprender com sentido. São Paulo: Editora e Livraria Instituto Paulo Freire, 2008.

Galeano, E. As palavras andantes. 5. ed. Porto Alegre: L\&PM, 2007.

Giddens, A. As consequências da modernidade. 2. ed. São Paulo: UNESP Editora, 1991.

Guerra, A. J. T.; Coelho, M. C. N. (Org.). Unidades de conservação: abordagens e características geográficas. Rio de Janeiro: Bertrand Brasil, 2009.

ICMBio - Instituto Chico Mendes de Conservação da Biodiversidade. Quem somos. Disponível em: <http://www.icmbio. gov.br/portal>. Acesso em: 10 dez. 2011.

Kern, D. C. et al. As Terras Pretas de Índio na Amazônia: evolução do conhecimento em Terra Preta de Índio. Disponível em: $<$ http://www.biochar.org/joomla/images/stories/Cap_6_Dirse. pdf $>$. Acesso em: 14 abr. 2014.

Leff, E. Saber ambiental: sustentabilidade, racionalidade, complexidade, poder. Trad. Lúcia Mathilde Endlich Orth. 8. ed. Petrópolis: Vozes, 2011.

Molina, M. C. Políticas públicas. In: Caldart, R. S. (Org.). Dicionário da Educação do Campo. Rio de Janeiro, São Paulo: Escola Politécnica de Saúde Joaquim Venâncio, Expressão Popular, 2012, p. 585-594.

Nascimento, A. L. C. do. Um olhar sobre as Escolas-Família Agrícola Agroextrativista do Amapá: práticas e significados. In: Simonian, L. T. L. (Org.). Políticas públicas, desenvolvimento, unidades de conservação e outros contextos socioambientais no Amapá. Belém: Editora do NAEA; MPEAP, 2010. p. 361-395.

Posey, D. A. Exploração da biodiversidade e do conhecimento indígena na América Latina: desafios à sobrevivência e a velha ordem. In: Cavalcanti, C. (Org.). Meio ambiente, desenvolvimento sustentável e políticas públicas. São Paulo: Cortez; Recife: Fundação Joaquim Nabuco, 1997, p. 345-368.

Ramos, M. Possibilidades e desafios na organização do currículo integrado. In: Frigotto, G.; Ciavatta, M.; Ramos, M.
Ensino médio integrado: concepções e contradições. São Paulo: Cortez, 2005.

Reis, N. da S. Educação e alternância: notas para o debate social. Disponível em: $<\mathrm{http} / /$ www.red-ler.org/educacao-alternancia-notas.pdf $>$. Acesso em: 02 abr. 2011.

Rodrigues, J. A. Práticas discursivas de reprodução e diferenciação na pedagogia da alternância. 214f. Vitória, Tese (Doutorado em Educação) - Programa de Pós-Graduação em Educação do Centro de Educação da Universidade Federal do Espírito Santo, 2008.

Roué, M. Novas perspectivas em Etnoecologia: "saberes tradicionais" e gestão dos recursos naturais. In: Castro, E.; Pinton, F. (Org.). Faces do trópico úmido: conceitos e novas questões sobre desenvolvimento e meio ambiente. Belém: Editora SEJUP/UFPA-NAEA, 1997. p. 201-217.

Santos, A. R. dos. Metodologia científica: a construção do conhecimento. 4. ed. Rio de Janeiro: DP\&A Editora, 2001.

Schiavo, M. R.; Moreira, E. N. Glossário social. Rio de Janeiro: Comunicarte, 2005.

Severino, A. J. Metodologia do trabalho científico. 23. ed. São Paulo: Cortez, 2007.

Silva, J. B. da. Sustentabilidade institucional e participação comunitária da Reserva Extrativista Rio Cajari. Belém, Dissertação (Mestrado em Planejamento do Desenvolvimento) - PLADES/NAEA/UFPA, 2003.

Silva, J. B. da. Unidades de conservação e organizações de populações tradicionais sul-amapaenses: problemas, tendências e perspectivas. 377f. Belém, Tese (Doutorado em Desenvolvimento Socioambiental) - PDTU/NAEA/UFPA, 2007.

Silva, J. B. da. Elementos para a construção do sentido e o significado do conceito de população tradicional e sua importância para o século XXI. Revista de Humanidades do Curso de Ciências Sociais da UNIFAP, 3, 83-92, 2010a.

Silva, J. B. da. Populações tradicionais sul-amapaenses de Unidades de Conservação: valores, condutas e o papel da pedagogia da alternância. In: Simonian, L. T. L. (Org.). Políticas públicas, desenvolvimento, Unidades de Conservação e outras questões socioambientais no Amapá. Belém: NAEA; MPEAP, 2010b. p. 287-324.

Silva, J. B. da. Populações tradicionais, ação comunitária, capital social e educação: um debate necessário à efetivação de reservas extrativistas na Amazônia. Revista Margens, 6(10), 11-32, 2014. 
Silva, M. D. M. da; Simonian, L. T. L.; Amaral Filho, O. A publicidade e a definição de regras quanto ao uso do conceito de sustentabilidade. Revista Razón y Palabra, 85, 1-22, dic. 2013 a mar. 2014.

Simonian, L. T. L. Políticas públicas, desenvolvimento sustentável e recursos naturais em áreas de reservas na Amazônia brasileira. In: Coelho, M. C. N.; Simonian, L. T. L.; Fenzl, N. (Org.). Estado e políticas públicas na Amazônia: gestão de recursos naturais. Belém: CEJUP, 2000. p. 9-53.

Simonian, L. T. L. Floresta Nacional do Amapá: breve histórico, políticas públicas e (in)sustentabilidade. Papers do NAEA, 167, 2003.

Simonian, L. T. L. et al. Tendências recentes quanto à sustentabilidade no uso dos recursos naturais pelas populações tradicionais amazônicas. In: Aragón, E. (Org.). Populações e meio ambiente na Pan-Amazônia. Belém: NAEA, 2007. p. 25-44.
Sófocles. Édipo Rei. Minas Gerais: M\&M Editores Ltda. [Virtual Books Online]. Disponível em: <www.virtualbooks. com.br/>. Acesso em: 10 jan. 2011.

Vianna, L. P. De invisiveis a protagonistas: populações tradicionais e unidades de conservação. São Paulo: Annablume; FAPESP, 2008.

Weber, M. Metodologia das ciências sociais. Trad. Augustin Wernert. São Paulo: Cortez; Campinas-SP: Editora da Universidade de Campinas, 1992.

Weber, M. A dominação. Política e Sociedade, 1(2), 9-20, 1996.

Weber, M. Economia e sociedade. Brasília: Editora Universidade de Brasília, 1999.

Weber, M. A ética protestante e o "espírito" do capitalismo. São Paulo: Companhia das Letras, 2004. 